\title{
Effect of heat and film thickness on a photoinduced phase transition in azobenzene liquid crystalline polyesters
}

\author{
Sanchez, C; Alcala, R; Hvilsted, Søren; Ramanujam, P.S.
}

Published in:

Journal of Applied Physics

Link to article, DOI:

$10.1063 / 1.1560852$

Publication date:

2003

Document Version

Publisher's PDF, also known as Version of record

Link back to DTU Orbit

Citation (APA):

Sanchez, C., Alcala, R., Hvilsted, S., \& Ramanujam, P. S. (2003). Effect of heat and film thickness on a photoinduced phase transition in azobenzene liquid crystalline polyesters. Journal of Applied Physics, 93(8), 4454-4460. https://doi.org/10.1063/1.1560852

\section{General rights}

Copyright and moral rights for the publications made accessible in the public portal are retained by the authors and/or other copyright owners and it is a condition of accessing publications that users recognise and abide by the legal requirements associated with these rights.

- Users may download and print one copy of any publication from the public portal for the purpose of private study or research.

- You may not further distribute the material or use it for any profit-making activity or commercial gain

- You may freely distribute the URL identifying the publication in the public portal 


\title{
Effect of heat and film thickness on a photoinduced phase transition in azobenzene liquid crystalline polyesters
}

\author{
C. Sánchez and R. Alcaláa) \\ Departamento de Física de la Materia Condensada, ICMA, Universidad de Zaragoza-CSIC, \\ 50009 Zaragoza, Spain \\ S. Hvilsted \\ Department of Chemical Engineering, Danish Polymer Centre, Technical University of Denmark, \\ DK-2800 Kgs Lyngby, Denmark \\ P. S. Ramanujam \\ Risø National Laboratory, DK-4000 Roskilde, Denmark
}

(Received 13 November 2001; accepted 23 January 2003)

\begin{abstract}
The liquid crystal to isotropic phase transition induced with $488 \mathrm{~nm}$ light in films of liquid crystalline azobenzene polyesters has been studied as a function of temperature, light intensity, and film thickness. That phase transition is associated with the photoinduced trans-cis-trans isomerizations of azobenzene molecules and it has been found that the $488 \mathrm{~nm}$ light power needed to induce the transition to the isotropic state increases when the film thickness decreases. The irradiation with the laser beam heats the film up and this seems to be responsible for the observed thickness dependence. Optical absorption measurements show that azobenzene aggregates present in one of the polymers are broken down in the photoinduced phase transition. The birefringence induced with low power $488 \mathrm{~nm}$ light in films before and after undergoing that photoinduced phase transition has also been studied. Birefringence shows a faster growing rate in films which have undergone the transition. (C) 2003 American Institute of Physics. [DOI: 10.1063/1.1560852]
\end{abstract}

\section{INTRODUCTION}

Photoinduced effects in liquid crystalline (LC) azobenzene polymers have been extensively studied from both basic and applied points of view. ${ }^{1-7}$ Irradiation with light in the absorption bands of the azobenzenes [blue and ultraviolet (UV) regions] induces trans-cis-trans isomerizations and molecular reorientations. Optical dichroism and birefringence $(\Delta n)$ can be achieved using polarized light. For a given sample the time evolution and saturation values of these properties depend on sample temperature and light power. ${ }^{8,9}$ If this power is high enough, a phase transition from a mesogenic to an isotropic state can also be induced. ${ }^{10}$

Several studies have been performed on this transition in different LC polyacrylates with azobenzene groups in the side chain. ${ }^{11-13}$ It has been proposed that the photoinduced transition is not associated with an increase of the sample temperature due to the absorption of light in the film, but to an increase of the cis concentration. ${ }^{3}$ Whereas the elongated shape of trans isomer favors a mesogenic behavior in the polymer the bent configuration of cis isomer disturbs the LC phase. ${ }^{14}$ In this way, the cis concentration produced by strong illumination in the absorption bands of trans molecules can induce a decrease of the clearing point temperature $\left(T_{c}\right)$ of the polymer and a transition to the isotropic state can be reached.

Although the influence of heating due to the absorption of light can likely be neglected for low irradiation powers, ${ }^{15}$

a) Author to whom correspondence should be addressed; electronic mail: ralcala@posta.unizar.es it could be important when high power is needed to induce the phase transition. In some experiments performed in our group with LC azobenzene side chain polyesters, it has been found that the light power needed to induce the transition is strongly dependent on film thickness. Since the films used were about $1 \mu \mathrm{m}$ thick, it is unlikely that this dependence is due to interactions between the polymer film and the glass substrate. A heating of the film induced by the incident light could be the reason for the observed thickness dependence.

To check this possibility as well as to get a deeper insight into that phase transition in LC azobenzene polyesters, we have performed a study of the photoinduced birefringence in two azobenzene polyesters ( $P 6 a 4$ and $P 6 a 12)$ under illumination with linearly polarized $488 \mathrm{~nm}$ light from an Ar laser. The influence of sample temperature, light intensity, and thickness of the polymer film has been explored. The photoinduced changes in the optical absorption of the films as well as their optical response before and after inducing the transition have also been studied. The results are discussed taking into account trans and cis populations as well as molecular reorientations and the heating induced by the exciting light.

\section{EXPERIMENT}

The chemical structure of the polymers P6a4 and P6a12 used in this study is shown in Fig. 1(a), while the trans and cis configurations of the azo chromophore are given in Fig. 1(b). The synthesis and characterization of these polymers have been published elsewhere. ${ }^{10,16}$ Molecular masses of the polymers were measured by size-exclusion 
(a)

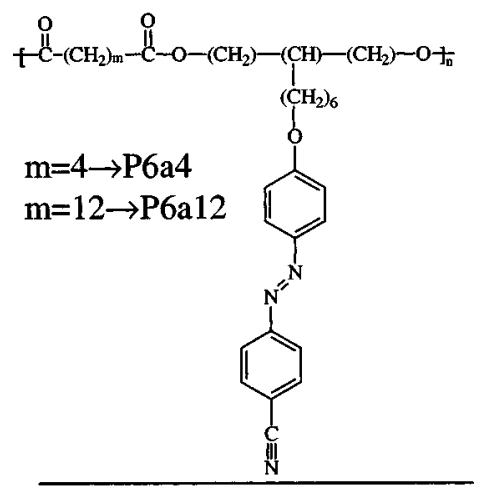

(b)

trans isomer

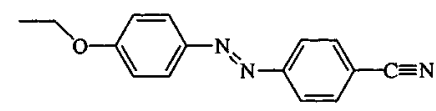

cis isomer

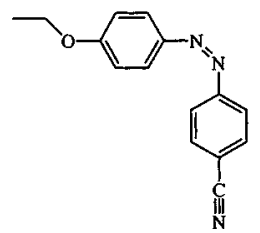

FIG. 1. (a) Chemical structure of the polyesters $P 6 a 4$ and $P 6 a 12$ and (b) trans and cis configurations of an azobenzene moiety.

chromatographic analysis and values of $M_{w}=42000$ and $M_{n}=21000$ for $P 6 a 4$ and $M_{w}=95000$ and $M_{n}=51000$ for $P 6 a 12$ were obtained using polystyrene calibration standards. The $P 6 a 4$ polyester shows a smectic $\left(S_{A}\right)$ mesophase between 45 and $59^{\circ} \mathrm{C}$, although the polymer crystallizes only upon prolonged annealing at room temperature (RT).$^{17}$ The glass transition temperature $\left(T_{g}\right)$ of this polymer is $\sim 10^{\circ} \mathrm{C}$. The polyester $P 6 a 12$ has a glass transition around $20^{\circ} \mathrm{C}$ and an ordered mesophase, tentatively ascribed to a $S_{A}$ phase, with a clearing temperature $\left(T_{c}\right)$ of 54 . Prolonged annealing in the mesophase range can derive in the formation of crystalline domains that melt at $72{ }^{\circ} \mathrm{C} .{ }^{16}$

Films were produced by casting a solution of the polymers in chloroform $(0.5-1.5 \mathrm{mg}$ in $200 \mu \mathrm{l})$ onto clean glass substrates. Thickness was measured using a DEKTAK profilometer. Before performing any experiment, films were heated up to $80^{\circ} \mathrm{C}$ (above the $T_{c}$ values of both polymers) during several minutes in order to erase any influence of the morphology induced during the preparation process as well as any previously photoinduced effect. Films were then fast quenched to RT by putting them on a metallic plate.

Optical absorption measurements have been performed in a Cary 500 Scan UV-visible near infrared spectrophotometer. Linear (vertical/horizontal) polarization of the measuring beams was achieved using a Glan-Thomson prism. Photoinduced anisotropy measurements were performed using the setup shown in Fig. 2. The sample was mounted on a hot stage with an optical access. A $488 \mathrm{~nm}$ vertically polar- crossed polarizers

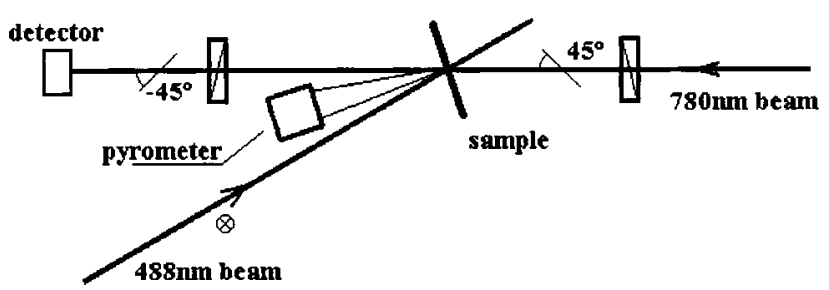

FIG. 2. Experimental setup for birefringence and film temperature measurements.

ized light beam (4 $\mathrm{mm}$ in diameter) from an Ar laser was used as the pumping light source. The sample was placed between crossed polarizers with their polarization directions at $\pm 45^{\circ}$ with the vertical axis. The light from a $780 \mathrm{~nm}$ diode laser transmitted through the polarizer-sample-polarizer system was measured with a Si detector as a probe of the photoinduced anisotropy. The transmitted intensity $I$ is given by the equation:

$$
I=I_{0} \sin ^{2}(\pi|\Delta n| d / \lambda),
$$

where $I_{0}$ is the intensity transmitted with parallel polarizers, without the sample, $d$ the film thickness, $\Delta n$ the birefringence of the sample, and $\lambda$ the wavelength of the measuring light $(780 \mathrm{~nm})$. In isotropic samples, no transmitted light is expected and thus, birefringence measurements enable us to detect the transition to an isotropic state. An optical pyrometer was used to measure the temperature of the film. The optical field of view of the pyrometer sensor head was adjusted to fall within the area illuminated by the Ar laser.

\section{RESULTS AND DISCUSSION}

The polymer films have been examined in the polarization microscope before and after irradiation with $488 \mathrm{~nm}$ linearly polarized light. From now on low/high power 488 $\mathrm{nm}$ light means that the power was below/above the threshold needed to induce the transition in that particular sample. A detailed account of the powers used will be given when we describe birefringence measurements.

Fast-quenched films show an isotropic microdomain structure. The light transmitted between crossed polarizers does not change with the film orientation indicating a random alignment of liquid crystalline domains. After irradiation with low power $488 \mathrm{~nm}$ linearly polarized light, a microdomain structure, similar to the one of the nonirradiated films is observed, while optical anisotropy is induced in the film. No light transmission is observed when the film direction corresponding to the polarization of $488 \mathrm{~nm}$ light is either perpendicular or parallel to the transmission direction of the polarizers. This behavior corresponds to the preferential orientation of the trans molecules (through the transcis-trans isomerization processes) in a plane perpendicular to the polarization direction of $488 \mathrm{~nm}$ light (see below).

In films irradiated with high power $488 \mathrm{~nm}$ linearly polarized light, a domain structure is barely observed and the light scattering produced by the film is drastically reduced. Besides, no light transmission is observed between crossed 
(a)

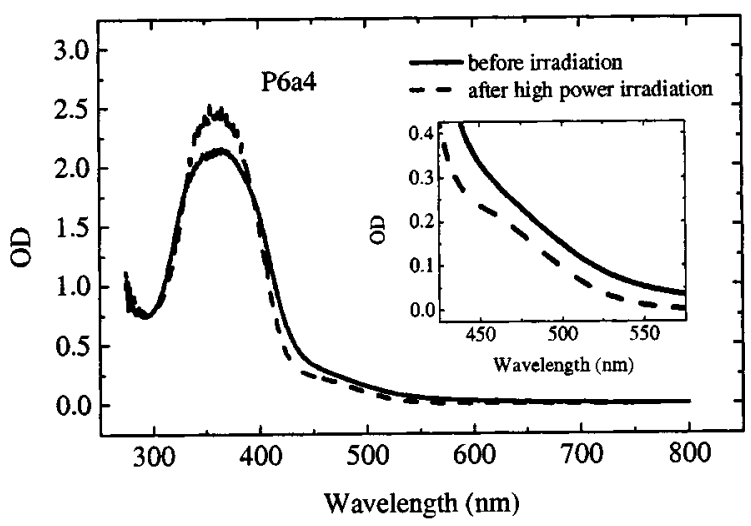

(b)

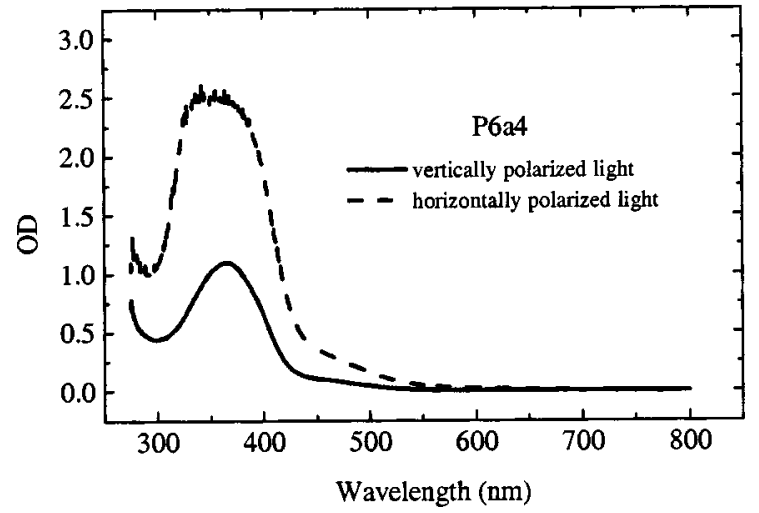

FIG. 3. Optical absorption and photoinduced dichroism in P6a4 films: (a) (—) before irradiation with $488 \mathrm{~nm}$ light, $(---)$ after irradiation with high power $488 \mathrm{~nm}$ light and (b) dichroism induced with low power vertically polarized 488 light: ( $(-)$ measured with vertically polarized light and (- - $)$ measured with horizontally polarized light. The inset in (a) shows a detailed view of the region around $450 \mathrm{~nm}$.

polarizers for any orientation of the film. These results indicate that after high power irradiation an isotropic state has been reached.

The polarized absorption spectrum of the films has also been measured before and after irradiation with $488 \mathrm{~nm}$ linearly polarized light. The results are shown in Figs. 3 and 4 for P6a4 and P6a12 films, respectively. Before irradiation with $488 \mathrm{~nm}$ light the azobenzene molecules are in the trans state. The absorption spectrum shows a main absorption band at about $370 \mathrm{~nm}$ and a shoulder at about $470 \mathrm{~nm}$ which corresponds to the $\pi-\pi^{*}$ and the $n-\pi^{*}$ transitions of the trans moiety, respectively. In the unirradiated films no difference has been found between the spectra measured with vertical and horizontal polarized light, as corresponds to an isotropic film.

After low power irradiation with linearly polarized 488 $\mathrm{nm}$ light a strong dichroism is observed in both $P 6 a 4$ and $P 6 a 12$ films, in agreement with the photoinduced orientation of trans molecules. Both, the trans and cis configuration of the azobenzene units [see Fig. 1(b)] show an absorption band in the $488 \mathrm{~nm}$ region associated with the $n \rightarrow \pi^{*}$ electronic transition. ${ }^{18}$ The dipolar moment of this transition is along (a)

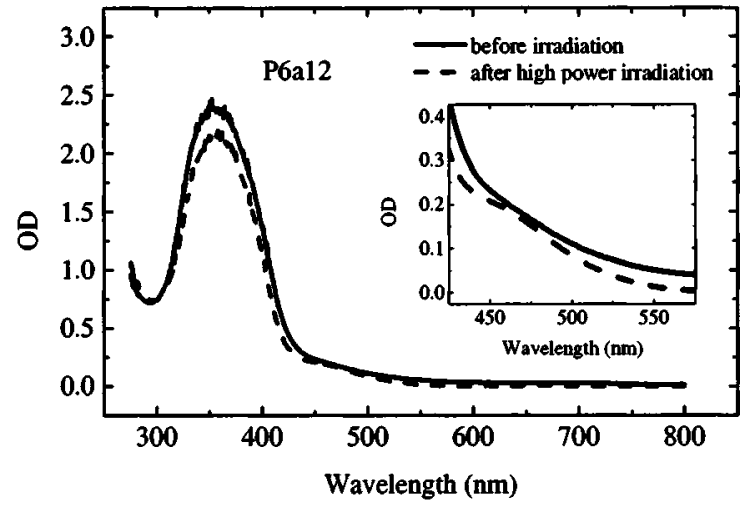

(b)

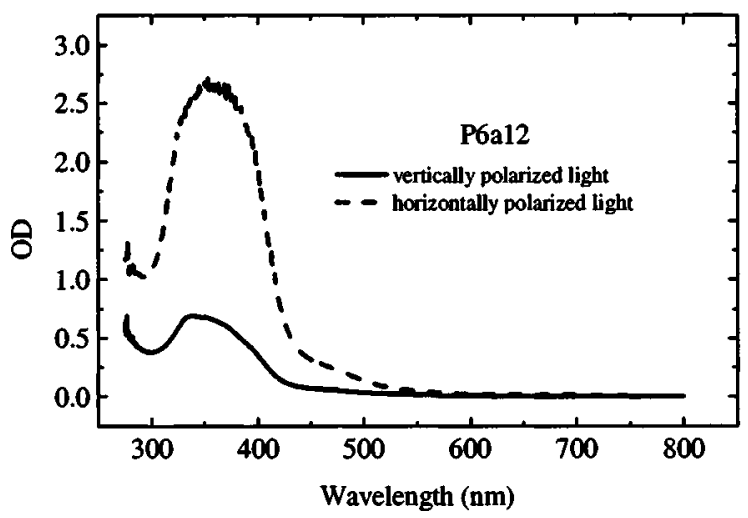

FIG. 4. Optical absorption and photoinduced dichroism in $P 6 a 12$ films: (a) ( - ) before irradiation with $488 \mathrm{~nm}$ light, $\left(-_{-}\right)$after irradiation with high power $488 \mathrm{~nm}$ light and (b) dichroism induced with low power vertically polarized 488 light: (_ ${ }_{-}$measured with vertically polarized light and $\left(--_{-}\right)$measured with horizontally polarized light. The inset in (a) shows a detailed view of the $450 \mathrm{~nm}$ region, where the $\left(--_{-}\right)$curve has been slightly shifted downwards for the sake of clarity.

the molecular axis for the trans isomer. Since the trans form is more stable at RT, the molecules will preferentially be in the trans configuration before irradiation. When the film is excited with $488 \mathrm{~nm}$ linearly polarized light, the trans molecules absorb it with an probability proportional to $\cos ^{2} \theta$, where $\theta$ is the angle between the molecular axis and the light polarization direction. The excited trans molecules are partly converted to the cis form, which can change its orientation before coming back to the trans state. In this way a preferential orientation of the trans molecules with its axis perpendicular to the polarization direction of the exciting light is achieved. ${ }^{18}$ This accounts for the observed dichroism.

After irradiation with high power $488 \mathrm{~nm}$ light no dichroism appears. As we will discuss later on, this is consistent with the photoinduced transition to an isotropic state. However, the behavior observed is different for the two polymers. In $P 6 a 12$ the main band at $370 \mathrm{~nm}$ slightly decreases (keeping the same form) and at the same time a small shoulder appears in the $450 \mathrm{~nm}$ region. This can be seen in the inset of Fig. 4(a) where, for the sake of clarity, the dashed curve has been slightly shifted downwards. The observed 


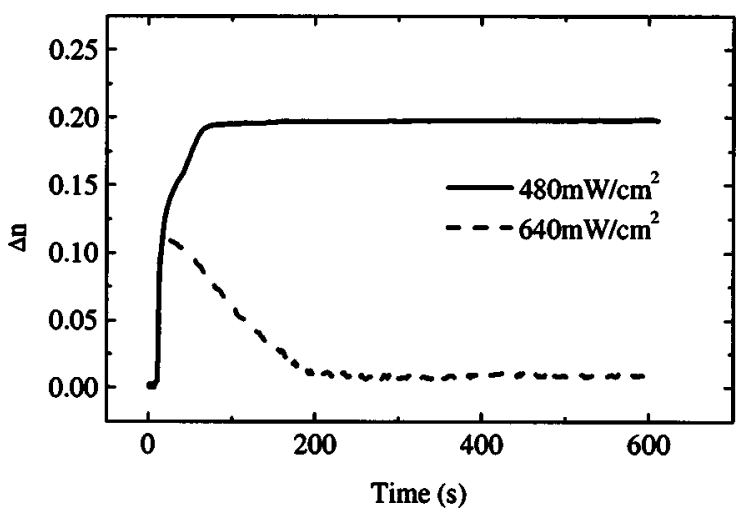

FIG. 5. Photoinduced birefringence in a $0.6 \mu \mathrm{m} \mathrm{P} 6 a 4$ film under $480 \mathrm{~mW} /$ $\mathrm{cm}^{2}(\longrightarrow)$ and $640 \mathrm{~mW} / \mathrm{cm}^{2}(---)$ incident 488 light power. At $t$ $=10 \mathrm{~s} \mathrm{light}$ of $488 \mathrm{~nm}$ is switched on until the end of the experiment. The initial temperature of the sample was set at $25^{\circ} \mathrm{C}$.

changes can be associated with a decrease in the concentration of trans molecules due to a partial transformation to the cis state, which has a absorption band at $450 \mathrm{~nm} .{ }^{19}$ However, in $P 6 a 4$ the appearance of the new shoulder at $450 \mathrm{~nm}$ [see inset in Fig. 3(a)] due to cis molecules is accompanied by an increase in the height and a narrowing of the $370 \mathrm{~nm}$ band.

A similar behavior has been observed by Geue et al. ${ }^{20}$ and Meier et al. ${ }^{21}$ in Langmuir-Blodgett multilayers and spin coated films of azobenzene polymers under UV irradiation. It has been associated by those authors to the breaking down of trans aggregates. In our case these aggregates would be present in the thermally quenched $P 6 a 4$ films but not in $P a 12$. It seems that the increase in length of the main chain spacer going from $P 6 a 4$ to $P 6 a 12$ precludes the formation of aggregates in the latter one. When the aggregates are broken, the concentration of nonaggregated trans molecules increases and so does the height of the $370 \mathrm{~nm}$ band. At the same time, the band due to the aggregates decreases and this can account of the narrowing of the $370 \mathrm{~nm}$ band.

The optical absorption measurements show that depending on the power of the $488 \mathrm{~nm}$ light we can either produce dichroism or induce a phase transition to an isotropic state. A more detailed study of the photoinduced effects has been performed by means of birefringence measurements. Birefringence was induced in the $P 6 a 4$ films by using different intensities (from 160 to $960 \mathrm{~mW} / \mathrm{cm}^{2}$ ) of the $488 \mathrm{~nm}$ linearly polarized light. Figure 5 shows the time evolution of $\Delta n$ for a $P 6 a 4$ film $0.6 \mu \mathrm{m}$ thick and $488 \mathrm{~nm}$ light powers of 480 and $640 \mathrm{~mW} / \mathrm{cm}^{2}$. The results with powers of 160 and 320 $\mathrm{mW} / \mathrm{cm}^{2}$ were similar to those with $480 \mathrm{~mW} / \mathrm{cm}^{2}$, while the ones with $640 \mathrm{~mW} / \mathrm{cm}^{2}$ were similar to those with higher light powers. The $488 \mathrm{~nm}$ light was made to fall upon the film at $t=10 \mathrm{~s}$. The temperature of the illuminated region of the film has also been measured. Before irradiation film temperature was set at $25^{\circ} \mathrm{C}$. Under irradiation with $480 \mathrm{~mW} /$ $\mathrm{cm}^{2}$ of $488 \mathrm{~nm}$ light, the temperature increase $(\Delta T)$ was about $1{ }^{\circ} \mathrm{C}$ which is the resolution limit of our pyrometer. For an incident power of $640 \mathrm{~mW} / \mathrm{cm}^{2}$ was about $3{ }^{\circ} \mathrm{C}$. Since these $\Delta T$ values are close to our experimental accuracy, a detailed study of the temperature evolution could not be performed with $P 6 a 4$ films.
It can be seen that with a power of $480 \mathrm{~mW} / \mathrm{cm}^{2}$ or below, $\Delta n$ increases with time and reaches a saturation value. When the incident power is $640 \mathrm{~mW} / \mathrm{cm}^{2}$ or above, $\Delta n$ shows an initial increase and then goes back to zero with no subsequent recovery. We associate that decrease of $\Delta n$ with the photoinduced phase transition to an isotropic phase. ${ }^{22}$ The film isotropy has been checked in a polarization microscope.

The same type of experiments was performed with 0.3 and $0.1 \mu \mathrm{m}$ thick samples. The results are similar to those in the $0.6 \mu \mathrm{m}$ film, the only difference being that the light power needed to induce the transition to the isotropic phase increases to about $1.6 \mathrm{~W} / \mathrm{cm}^{2}$ in the $0.3 \mu \mathrm{m}$ film and to about $3.3 \mathrm{~W} / \mathrm{cm}^{2}$ in the $0.1 \mu \mathrm{m}$ one. The temperatures of the films irradiated with powers just below and above the one needed to induce the transition were the same as those in the $0.6 \mu \mathrm{m}$ film within our experimental accuracy.

The higher values of light power needed to induce the transition in thinner films than in thicker ones could, in principle, have different explanations. On one side, the influence of the interaction between the film and the glass substrate, which can reduce the mobility of the molecules close to the interface, could be more important in the thinner films than in the thicker ones. There are many studies about the influence of substrate-film interaction on the properties of thin polymer films..$^{23-25}$ It seems that, in general, this influence is only important for very thin films (below $20 \mathrm{~nm}$ thick). Thus the interaction of the polymer with the substrate is unlikely to be the reason for the observed behavior in our films.

On the other hand, although the heating due to the absorption of $488 \mathrm{~nm}$ light is rather small in our experiments it could help, together with the necessary presence of cis molecules, to induce the phase transition. That being the case, since light absorption is less in the thinner films, higher light power will be needed to reach the same temperature in the thinner films than in the thicker ones and thus the phase transition will be induced with higher light power in the thinner films.

To check the influence of a small film heating on the transition temperature under $488 \mathrm{~nm}$ light illumination, we have measured the birefringence of thin films for different temperatures of the sample holder. It has been found that the light power needed to induce the transition strongly decreases with increasing temperature. Thus, if the initial temperature of the film was increased from 25 to $27^{\circ} \mathrm{C}$, the light power needed to induce the transition in the $0.1 \mu \mathrm{m}$ film was reduced from $3.3 \mathrm{~W} / \mathrm{cm}^{2}$ to about $640 \mathrm{~mW} / \mathrm{cm}^{2}$. For an initial temperature of $30^{\circ} \mathrm{C}$ or higher no permanent birefringence was induced in any of the films for light power of 160 $\mathrm{mW} / \mathrm{cm}^{2}$ and above. These results indicate that the photoinduced phase transition associated with the trans-cis isomerization is not directly influenced by the film thickness but by the photoinduced film heating.

The small temperature range in which birefringence can be induced in $P 6 a 4$ films does not allow us to perform a detailed study of the phase transition induced with $488 \mathrm{~nm}$ light under different experimental conditions. We have extended our measurements to $P 6 a 12$ to have a wider experimental range of both temperature and light power. In this 

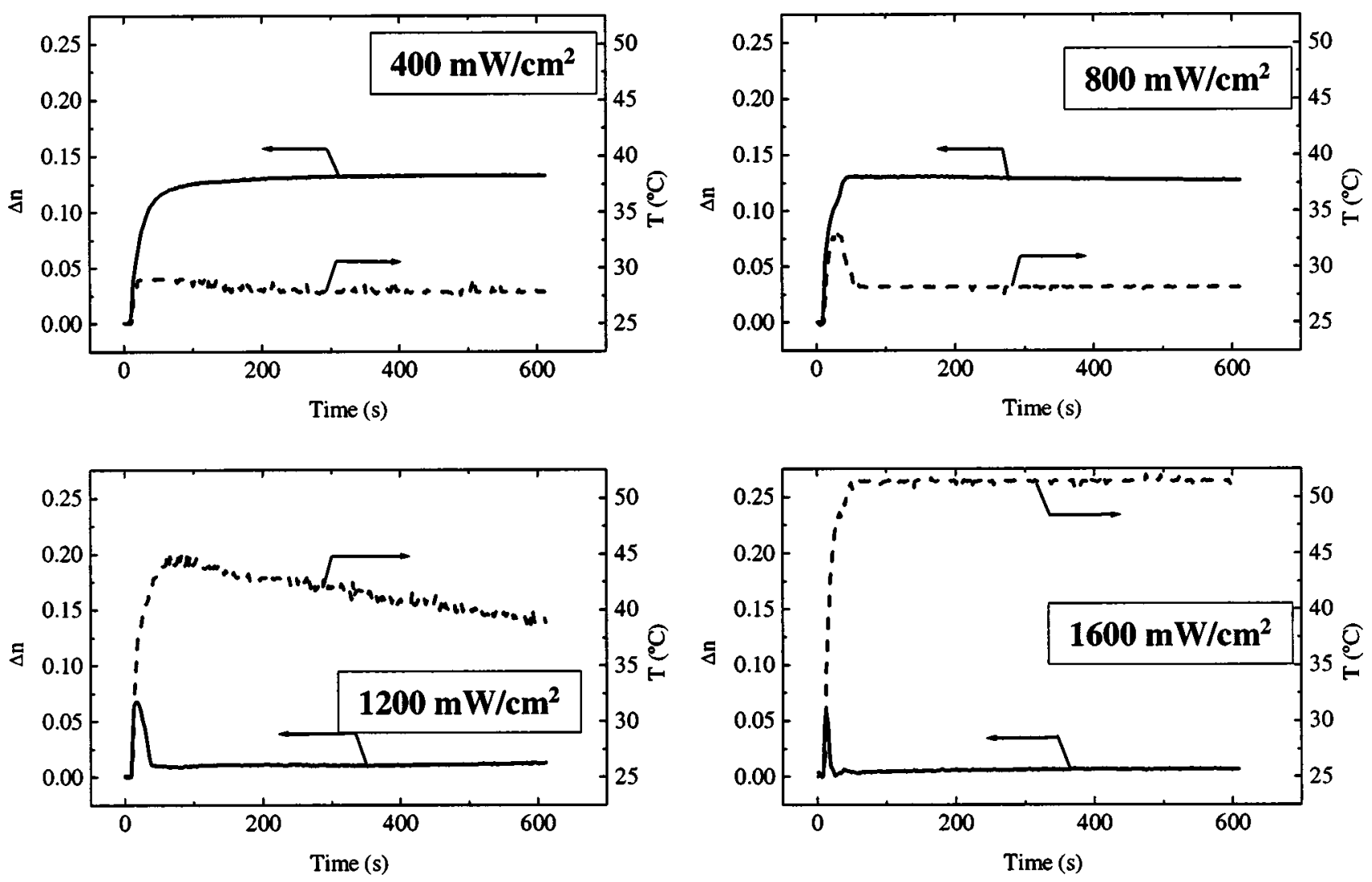

FIG. 6. Photoinduced birefringence (- ${ }^{-}$) and temperature (- - ) of a $2.1 \mu \mathrm{m}$ film of $P 6 a 12$ as a function of time at different irradiation power. At $t=10$ $\mathrm{s}$ the $488 \mathrm{~nm}$ light is switched on until the end of the experiment. The initial temperature of the sample was set at $25^{\circ} \mathrm{C}$.

polymer, even for films thicker than those of $P 6 a 4$, permanent birefringence was induced for initial temperatures up to $35^{\circ} \mathrm{C}$.

Films of three different thicknesses $(2.1,1.4$, and 0.6 $\mu \mathrm{m})$ have been used. With these thicknesses, which are larger than those of $P 6 a 4$ films, the possible effects of the interaction between the glass substrate and the polymer film would be reduced. However, the results were similar to those in P6a4 films. This shows again that the influence of the substrate-film interaction on the phase transition is not important in our case. Besides, the photoinduced temperature changes were larger in these thicker films than in those of $P 6 a 4$ and thus, they could be more easily measured with our pyrometer.

Figure 6 shows the evolution with time of both birefringence and film temperature for the $2.1 \mu \mathrm{m}$ film under different irradiation powers and an initial temperature of $25^{\circ} \mathrm{C}$. With an incident power of $400 \mathrm{~mW} / \mathrm{cm}^{2}, \Delta n$ increases when light is switched on, reaches a maximum value, and then remains stable. $T$ also increases at the beginning and then slowly decreases to an equilibrium value slightly above the initial one.

The $\Delta n$ evolution when the incident power was 800 $\mathrm{mW} / \mathrm{cm}^{2}$ is very close to that with $400 \mathrm{~mW} / \mathrm{cm}^{2}$ but the saturation value is reached in a shorter time. The evolution of film temperature is also similar to the one with $400 \mathrm{~mW} / \mathrm{cm}^{2}$ but the cooling of the film to its equilibrium temperature value is faster.
With $1.2 \mathrm{~W} / \mathrm{cm}^{2}, \Delta n$ shows a fast increase when light is switched on and then goes back to zero in about 20 s. $T$ increases at the beginning, and then slowly decreases. No equilibrium temperature has been achieved in this case after $600 \mathrm{~s}$ but, even after this time, $T$ is higher than the final one achieved with $800 \mathrm{~mW} / \mathrm{cm}^{2}$ power.

Finally with a power of $1.6 \mathrm{~W} / \mathrm{cm}^{2}$ (and up) $\Delta n$ shows a fast initial increase and then goes back to zero in few seconds while $T$ increases at the beginning and saturates after about $50 \mathrm{~s}$.

These results, as well as those in P6a4 films, can be qualitatively understood in the following way. For low light power the appearance of birefringence can be understood in the same way as the dichroism in optical absorption. Both are due to the photoinduced reorientation of the azobenzene molecules. Besides, for these low powers, the heating of the film as well as the cis concentration are small. As we said above, the increase in cis concentration produces a strong lowering of $T_{c}$ but, if this lowering is not enough to reach the actual temperature of the film, the phase transition does not take place and a permanent birefringence is observed.

For high light power there is a first stage in which birefringence is induced and temperature and cis concentration increases. Afterwards, one has to consider the interplay among irradiation intensity, absorption, temperature, and cis concentration. One has also to take into account the molecular reorientations as well as the optically induced cis-trans conversions, which change the optical absorption for linearly 


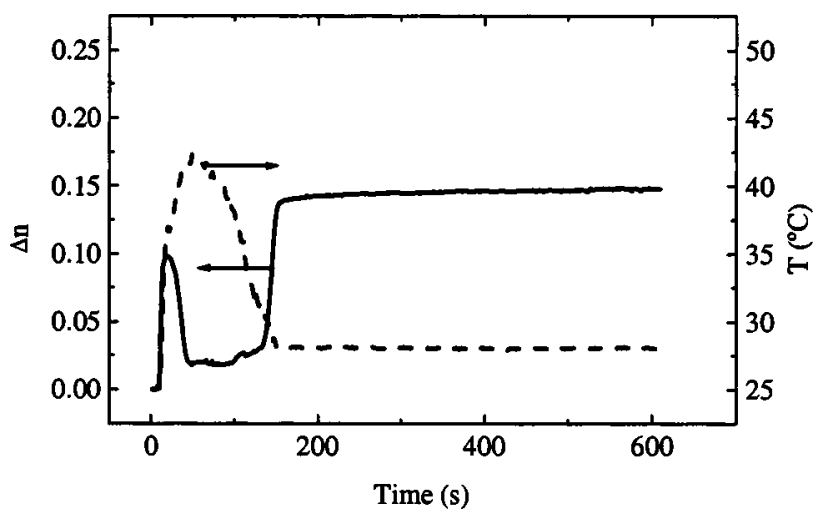

FIG. 7. Photoinduced birefringence (- $)$ and temperature $(---)$ of a $0.6 \mu \mathrm{m}$ film of $P 6 a 12$ as a function of time. The incident light power was $450 \mathrm{~mW} / \mathrm{cm}^{2}$. At $t=10 \mathrm{~s}$ the $488 \mathrm{~nm}$ light is switched on until the end of the experiment. The initial temperature of the sample was set at $25^{\circ} \mathrm{C}$.

polarized $488 \mathrm{~nm}$ light (see Figs. 3 and 4). A combination of light induced heating due to trans and cis absorption and lowering of $T_{c}$ will eventually give place to the transition to an isotropic phase. In this phase, temperature can be modified again due to the absorption changes associated with the evolution of trans and cis populations.

This qualitative explanation can also account for the results corresponding to initial film temperatures higher than $25^{\circ} \mathrm{C}$ in $P 6 a 4$. In all the films, the $T_{c}$ values under $488 \mathrm{~nm}$ light irradiation with power higher than $160 \mathrm{~mW} / \mathrm{cm}^{2}$ seem to be below $30^{\circ} \mathrm{C}$ and thus no permanent birefringence can be achieved at this temperature and above. On the other hand, when the initial temperature of the $0.1 \mu \mathrm{m}$ film is set at $27^{\circ} \mathrm{C}$, the increase in temperature needed to reach $T_{c}$ is smaller than for an initial temperature of $25^{\circ} \mathrm{C}$. Consequently, the phase transition can be induced with a much lower light power in the former case $\left(640 \mathrm{~mW} / \mathrm{cm}^{2}\right)$ than in the latter one $\left(3.3 \mathrm{~W} / \mathrm{cm}^{2}\right)$.

Finally, we want to point out that in all the $P 6 a 12$ films and for incident light power slightly below the threshold needed to induce the transition, a more complex evolution of $\Delta n$ with irradiation time is observed. Figure 7 shows an example of the evolution of $\Delta n$ and $T$ corresponding to the 0.6 $\mu \mathrm{m}$ film with an initial temperature of $25^{\circ} \mathrm{C}$ and a light power of $450 \mathrm{~mW} / \mathrm{cm}^{2} . \Delta n$ increases at the beginning and then decreases as for higher powers. However, in this case, $\Delta n$ increases again after about $150 \mathrm{~s}$ and saturates as for low power excitation. With respect to temperature, it increases at the beginning, keeps increasing even after $\Delta n$ disappears, and then decreases again and reaches a stationary value. To account for this complex behavior the complicate interplay between cis/trans concentrations, optical absorption temperature, and the photoinduced transition have to be taken into account although we cannot give a detailed explanation of it.

As for P6a4 we also tried to further check the influence of temperature on the power needed to induce the phase transition in P6a12 films. To do that we have performed birefringence measurements as a function of irradiation time changing the initial temperature of the films. The results are similar to those in $P 6 a 4$, with a decrease of the light power

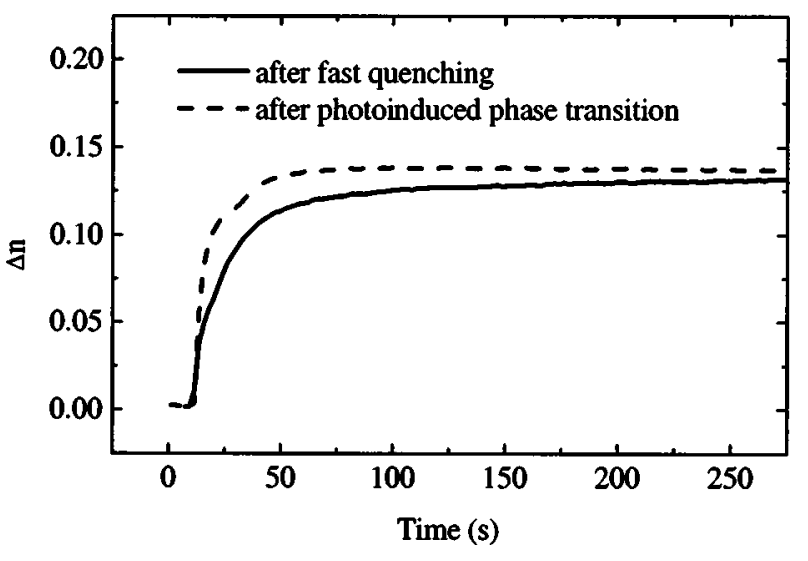

FIG. 8. Photoinduced birefringence recorded with $400 \mathrm{~mW} / \mathrm{cm}^{2}$ as a function of time in a $2.1 \mu \mathrm{m}$ film of P6a12: (— ) film after thermal quenching, $(---)$ film which has undergone the photoinduced phase transition. At $t=10 \mathrm{~s}$ the $488 \mathrm{~nm}$ light is switched on until the end of the experiment. The initial temperature of the sample was set at $25^{\circ} \mathrm{C}$.

needed to induce the transition when the initial temperature increases. This again indicates that the change in light power needed to induce the transition in films of different thickness is mainly due to temperature changes associated with the absorption of $488 \mathrm{~nm}$ light by the films.

This has been supported by another experiment in P6a 12 films. With an initial temperature of $25^{\circ} \mathrm{C}$ and a light power of $800 \mathrm{~mW} / \mathrm{cm}^{2}$ we have saturated the birefringence of the three films $(2.1,1.4$, and $0.6 \mu \mathrm{m}$ thick). Afterwards and keeping the same light power, the films have been heated up in $1^{\circ} \mathrm{C}$ steps until the birefringence goes back to zero (transition to the isotropic phase). It has been found that this transition temperature is the same for the three films $\left(42{ }^{\circ} \mathrm{C}\right.$ in our experimental conditions) as expected if temperature is the parameter that accounts for the observed thickness dependence. This also confirms previous observations ${ }^{8}$ that no anisotropy could be induced in $\mathrm{P} 6 \mathrm{a} 12$ by linearly polarized light (in $\sim 400 \mathrm{~nm}$ thick films) at $40{ }^{\circ} \mathrm{C}$ and above.

All the results reported up to now have been obtained in films previously heated to $80^{\circ} \mathrm{C}$ and fast cooled to RT. It has been reported that the response of $P 6 a 12$ films to polarized $488 \mathrm{~nm}$ light depends on the cooling rate from $80^{\circ} \mathrm{C}$ to $\mathrm{RT}^{8}{ }^{8}$ Faster response has been obtained in fast quenched films. This seems to be associated with differences in film microstructure.

The isotropic films obtained after the photoinduced phase transition, likely have a different microstructure than those obtained by fast quenching. Thus, we have investigated the influence of this change of microstructure on the evolution of the photoinduced birefringence. Since the observed behavior is similar for all the P6a4 and P6a12 films we only show the results corresponding to a $2.1 \mu \mathrm{m}$ film of the last polymer. The evolution of birefringence and film temperature under irradiation with $400 \mathrm{~mW} / \mathrm{cm}^{2}$ of $488 \mathrm{~nm}$ light have been compared in a film obtained by fast quenching and the same film after it has undergone the photoinduced phase transition. In both cases the temperature evolution was the same as that in Fig. 6 (for $400 \mathrm{~mW} / \mathrm{cm}^{2}$ ). The birefringence results are given in Fig. 8. it can be seen that the birefrin- 
gence in the films which have undergone the photoinduced transition, grows faster. It seems that the microstructure of the film is modified by the transition in such a way that molecular reorientations are more easily produced.

\section{CONCLUSIONS}

A detailed study of the photoinduced effects of $488 \mathrm{~nm}$ light on two azobenzene side chains LC polyesters has been performed. By irradiation with linearly polarized $488 \mathrm{~nm}$ light we have induced either an anisotropic optical behavior (for low exciting light power) or an isotropic phase (for high power). Besides, in the polymer with a shorter main chain spacer, in which some azobenzene aggregates seem to be present, the breaking down of these aggregates has been induced with high power irradiation. The transition to the isotropic phase, due to the photoinduced trans-cis isomerization, seems to be influenced by film thickness. The thicker the film, the lower the intensity needed to induce the transition to the isotropic phase. The increase of the film temperature due to light irradiation can account for the observed thickness dependence. A complicated evolution of birefringence with time has been observed depending on film thickness, temperature, and irradiation power.

The recording rate of birefringence is bigger in films that have undergone the photoinduced phase transition than in films thermally quenched from temperatures above $T_{c}$. Changes in the microstructure of the polymer have been proposed to account for these changes in the recording process.

\section{ACKNOWLEDGMENTS}

The financial support from the CICYT, Spain, under Project No. MAT99-1009-C02 is gratefully acknowledged. The authors gratefully acknowledge Dr. Anibal Reñones from CARTIF (Parque Tecnológico de Boecillo, Valladolid, Spain) for his support in the pyrometric measurements.
${ }^{1}$ M. Eich and J. H. Wendorff, J. Opt. Soc. Am. B 7, 1428 (1990).

${ }^{2}$ R. Rochon, J. Gosselin, A. Natansohn, and S. Xie, Appl. Phys. Lett. 60, 4 (1992).

${ }^{3}$ T. Ikeda and O. Tsutsumi, Science 268, 1873 (1995).

${ }^{4}$ R. H. Berg, S. Hvilsted, and P. S. Ramanujam, Nature (London) 383, 505 (1996).

${ }^{5}$ S. J. Zilker, T. Bieringer, D. Haarer, R. S. Stein, J. W. van Egmond, and S. G. Kostromine, Adv. Mater. 10, 855 (1998).

${ }^{6}$ J. A. Delaire and K. Nakatani, Chem. Rev. 100, 1817 (2000).

${ }^{7}$ S. Kurihara, A. Sakamoto, D. Yoneyama, and T. Nonaka, Macromolecules 32, 6493 (1999).

${ }^{8}$ N. C. R. Holme, P. S. Ramanujam, and S. Hvilsted, Appl. Opt. 35, 4622 (1996).

${ }^{9}$ Y. Wu, Y. Demachi, O. Tsutsumi, A. Kanazawa, T. Shiono, and T. Ikeda, Macromolecules 31, 349 (1998).

${ }^{10}$ P. S. Ramanujam, S. Hvilsted, and F. Andruzzi, Appl. Phys. Lett. 62, 1041 (1993).

${ }^{11}$ O. Tsutsumi, T. Kitsunai, A. Kanazawa, T. Shiono, and T. Ikeda, Macromolecules 31, 355 (1998).

${ }^{12}$ O. Tsutsumi, Y. Demachi, A. Kanazawa, T. Shiono, T. Ikeda, and Y. Nagase, J. Phys. Chem. B 102, 2869 (1998).

${ }^{13}$ M. Hasegawa, T. Yamamoto, A. Kanazawa, T. Shiono, and T. Ikeda, Chem. Mater. 11, 2764 (1999).

${ }^{14}$ S. Xie, A. Natansohn, and P. Rochon, Chem. Mater. 5, 403 (1993).

${ }^{15}$ S. Bauer-Gogonea, S. Bauer, W. Wirges, and R. Gerhard-Multhaupt, J. Appl. Phys. 76, 2627 (1994).

${ }^{16}$ S. Hvilsted, F. Andruzzi, C. Kulinna, H. W. Siesler, and P. S. Ramanujam, Macromolecules 28, 2172 (1995)

${ }^{17}$ E. L. Tassi, M. Paci, P. L. Magagnini, B. Yang, O. Francescangeli, and F. Rustichelli, Liq. Cryst. 24, 457 (1998).

${ }^{18}$ T. Bieringer, in Hologrpahic Data Storage, edited by H. J. Coufal, D. Psaltis, and G. T. Sincerbox (Springer, Berlin, 2000).

${ }^{19}$ P. S. Ramanujam, H. Hvilsted, I. Zebger, and H. W. Siesler, Macromol. Rapid Commun. 16, 455 (1995).

${ }^{20}$ Th. Geue, A. Ziegler, and J. Stumpe, Macromolecules 30, 5729 (1997).

${ }^{21}$ J. G. Meier, R. Ruhmann, and J. Stumpe, Macromolecules 33, 843 (2000).

${ }^{22}$ T. Sasaki, T. Ikeda, and K. Ichimura, Macromolecules 25, 3807 (1992).

${ }^{23}$ J. H. van Zanten, W. E. Wallace, and W. Wu, Phys. Rev. E 53, 2053 (1996).

${ }^{24}$ K. Fukao and M. Miyamoto, Phys. Rev. E 61, 1743 (2000).

${ }^{25}$ L. Cristofolini, S. Arisi, and M. P. Fontana, Phys. Rev. Lett. 85, 4912 (2000) 